\title{
Screening antibacterial activity ODS fractions of marine sponges against non-pathogenic bacteria tuberculosis Mycobacterium smegmatis
}

\author{
Deiske A. Sumilat \\ Faculty of Fisheries and Marine Science, Sam Ratulangi University. Campus Unsrat Manado 95115 \\ E-mail: deiske.sumilat@unsrat.ac.id
}

Received: 20 February 2021 - Revised: 6 April 2021 - Accepted: 6 April 2021

\begin{abstract}
Nine unidentified marine sponges from Bunaken Island waters in Manado Indonesia were observed on antituberculosis (TB) against non-pathogenic Mycobacterium smegmatis NBRC 3207 and it was found that the ethanol crude extracts and ODS fractions of these sponges inhibited the growth of bacteria M. smegmatis. Sponge SP.323 is the most inhibiting and showed Intermediate (I) activity with inhibition zones of 9, 11, 11, $8 \mathrm{~mm} /$ disk at $10 \mu \mathrm{g} /$ disk., for fraction 3,4,5,6 respectively, and need further experimental analysis to justify the antimicrobial activity, NMR analysis and structure elucidation.
\end{abstract}

Keywords: sponges; antibacterial; tuberculosis; Mycobacterium smegmatis; ODS

\section{INTRODUCTION}

Tuberculosis (TB) disease is one of the top 10 causes of death and the leading cause from a single infectious agent (above HIV/AIDS). Tuberculosis (TB) caused by Mycobacterium tuberculosis is still one of the main infectious diseases in the the world, including with the human immunodeficiency virus (HIV) and malaria (WHO, 2020). According to World Health Organization (WHO), around 10 million people continue to fall sick with $\mathrm{TB}$ each year with the leading cause of $M$. tuberculosis. In 2019, TB caused an estimated 1.2 million deaths (range, 1.1-1.3 million) among HIV-negative people and there were an additional 208.000 deaths from TB (range, 177.000-242.000) among HIV-positive people (WHO, 2020). Because of lack of treatment or lack of adapting treatment, many researchers are interested to find antituberculotic drugs. Urgent action is required to improve the coverage and quality of diagnosis, treatment and care for people with drug-resistant TB.

Marine organisms such as invertebrate are a much sought-after sources of drugs candidate. Sponges are exclusively aquatic animals that dominate in many benthic habitats, are rich source of biologically active natural products with unique structures (Caroll et al., 2020). Sponges are thought to be used for pharmaceutical and biotechnological industries and have shown the highest potential for natural product discovery (Mehbub et al., 2014). A number of metabolites have been isolated and they were found to have various biological activities, such as antibacterial, antifungal, anti-HIV, antiinflammatory, anticancer, and as enzyme inhibitory activities (Mehbub et al., 2014). Some sponge derived natural and synthetic compounds have been approved for clinical use (Newman and Cragg, 2014; 2020), such as Eribulin (an anticancer agent). Therefore, marine metabolites might be developed as a new recommended source of promising drugs.

For several years our research has focused on antimicrobials with purpose to find new antimycobacterial substances from marine sponges and microorganisms collected in North Sulawesi, Indonesia. We found microbe M. smegmatis which has often been used in molecular biological experiments and experimental tuberculosis as a substitute of highly pathogenic M. tuberculosis.

Mycobacterium smegmatis is used as an alternative microorganism to detect antibacterial activity against tuberculous bacteria. During our group research on sponges, we found antimycobacterial activity of a bisfunctionalized sphingolipid from marine sponge Agelas sp. collected in Manado (Abdjul et al., 2017), that was 
Sumilat: Screening antibacterial activity ODS fractions of marine sponges against non-pathogenic ...

the first study to show that Agelas sp. inhibited the growth of M. smegmatis. Three new dimeric 3-alkyl pyridinium alkaloids, called haliclocyclamines $\mathrm{A}-\mathrm{C}$, were found from Indonesian marine sponge Haliclona sp. and showed inhibited antimicrobial activities against M. smegmatis (Maarisit et al., 2017). On the screening of antimicrobial, it was found that the ethanol extract ODS fractions of an Indonesian marine sponge Auletta sp. inhibited the growth of nonpathogenic M. smegmatis (Sumilat, 2019).

In the course to continue studies on anti-TB metabolites from Indonesian marine sponges we have tested nine unidentified species of marine sponges against $M$. smegmatis NBRC 3207 and found that the crude extracts and ODS fractions of these nine sponges exhibited prominent activity.

\section{MATERIALS AND METHODS}

\section{Experimental Procedures}

The chemicals and solvents; Ethanol, Methanol, Glycerol, Agar, Potato Dextrose Agar, Peptone, Glucose, Sucrose, Yeast Extract, Paper disk, ODS C-18 were purchased from Wako Pure Chemical Industries Ltd. (Osaka, Japan). Fetal bovine serum (FBS) was purchased from Invitrogen (Carlsbad, CA, USA). Middlebrook 7H9 broth, polysorbate 80, and Middlebrook OADC were purchased from $\mathrm{BD}$.

\section{Sample Collection and Extraction}

Marine sponges were collected by scuba diving at Bunaken Island in Manado Indonesia, in 2014. The nine-voucher specimens were deposited at the Faculty of Pharmaceutical Sciences, Tohoku Medical and Pharmaceutical University.

Marine sponge was cut into small parts and put in a bottle containing ethanol $500 \mathrm{ml}$, kept at room temperature for $1 \times 24 \mathrm{~h}$. The ethanol extracted was filtered and subjected to the rotary evaporator for drying to obtain the final weight (Ebada et al., 2008).

\section{Microbes}

The strain of M. smegmatis NBRC 3207 was obtained from the Biological Resource Center (NBRC), NITE (Chiba, Japan) and was maintained in $20 \%$ glycerol a t $-80{ }^{\circ} \mathrm{C}$.

The strain of Candida albicans IFM 4954 (Yeast); Mucor hiemalis IAM 6088 (Filamentous fungus); Staphylococcus aureus IAM 12544T (Gram-positive); Escherichia coli IAM 12119T (Gram-negative); were obtained from Faculty of Pharmaceutical Sciences, Tohoku Medical and Pharmaceutical University, Japan, and were maintained at $-80{ }^{\circ} \mathrm{C}$.

\section{Column Chromatography}

The ethanol extract was evaporated, and the residue was separated into seven fractions (Frs. 1-7) by an ODS (octadecylsilane) column $(100 \mathrm{~g})$ with the stepwise elution of $\mathrm{CH}_{3} \mathrm{OH}$ in $\mathrm{H}_{2} \mathrm{O}$. $(0 \%, 20 \%, 40 \%$, $60 \%, 80 \%, 100 \%, 100 \%+0.05 \%$ TFA).

\section{Antimicrobial Assay}

The extracted of sponges were screening to examine the inhibitory activities on the growth of $C$. albicans (yeast), M. hiemalis (filamentous fungus), M. smegmatis, S. aureus (Gram-positive bacterium), E. coli (Gram-negative bacterium) (Bu et al., 2014; Abdjul et al., 2017; Maarisit et al., 2017).

ODS column chromatography was performed to separation in 7 fractions and screening to examine the inhibitory activities on the growth of $M$. smegmatis. The concentration of samples was arranged from 10, 20, $30 \mathrm{ug} / \mathrm{disk}$. M. smegmatis was cultured in Middlebrook $7 \mathrm{H} 9$ broth at $37^{\circ} \mathrm{C}$ for $6-12$ days and adjusted to $1.0 \times 106 \mathrm{CFU} / \mathrm{mL}$. The disk was placed on an agar plate and incubated for 2 days at $37^{\circ} \mathrm{C}$. Streptomycin sulfate and $\mathrm{CH}_{3} \mathrm{OH}$ were used as positive and negative controls, respectively. A zone of inhibition test in antibacterial assay was carried out using M. smegmatis NBRC 3207 by the paper disk method (CLSI, 2013). The interpretive diffusion disk consists of Susceptible $(\mathbf{S}) \geq 20 \mathrm{~mm}$, Intermediate (I) $15-19 \mathrm{~mm}$, Resistant (R) $\leq 14 \mathrm{~mm}$, where the sample concentration is $30 \mu \mathrm{g}$ (CLSI, 2013).

\section{Media Culture E. coli, S. aureus, C. albicans and M. hiemalis}

Media B-1 (liquid) for inoculate E. coli, $S$. aureus, and $C$. albicans were made of Peptone (polypeptone), meat extract, $\mathrm{NaCl}$ (Sodium Chloride), and $\mathrm{dH}_{2} \mathrm{O} 100 \mathrm{~mL}$. Strains E. coli, S. aureus, and $C$. albicans $1 \mathrm{~mL}$ respectively, then incubate at $37{ }^{\circ} \mathrm{C}$, for 1 days. Media B-1 (liquid) for inoculate M. hiemalis: Potato, sucrose, and $\mathrm{dH}_{2} \mathrm{O} 100$ $\mathrm{mL}$ at $25{ }^{\circ} \mathrm{C}$, and strains of $M$. hiemalis was incubate for 2 days ( $\mathrm{Bu}$ et al., 2014; Abdjul et al., 2017; Maarisit et al., 2017).

\section{Media Culture Middlebrook 7 H9 for $M$. smegmatis}

Broth dehydrated base of Middlebrook 7H9; containing $0.05 \%$ polysorbate $80,0.5 \%$ glycerol, and $10 \%$ Middlebrook OADC. Middlebrook OADC approx. per liter, containing 8.5 g Sodium Chloride; $50.0 \mathrm{~g}$ Bovine Albumin (Fraction V); $20.0 \mathrm{~g}$ 
Table 1. Antimicrobial assay of ethanol crude extracts from marine sponges

\begin{tabular}{|c|c|c|c|c|c|c|}
\hline \multirow{2}{*}{$\begin{array}{l}\text { Sample } \\
\text { Code }\end{array}$} & \multirow{2}{*}{$\begin{array}{l}\text { Weight } \\
(\mathrm{g})\end{array}$} & \multicolumn{5}{|c|}{ Assay Data (Inhibition Zone; mm; $50 \mu \mathrm{g} /$ disk) } \\
\hline & & E. coli & S. aureus & C. albicans & M. hiemalis & M. smegmatis \\
\hline SP. 102 & 27.72 & - & - & - & - & 12 \\
\hline SP. 135 & 12.40 & - & - & - & - & 11 \\
\hline SP. 137 & 22.05 & - & - & - & - & 8 \\
\hline SP. 205 & 6.40 & - & - & - & - & 10 \\
\hline SP. 206 & 10.50 & - & - & - & - & 10 \\
\hline SP. 259 & 0.85 & - & - & - & - & 7 \\
\hline SP. 323 & 1.75 & 7 & 8 & 7 & - & 10 \\
\hline SP. 352 & 2.25 & - & 7 & - & - & 8 \\
\hline SP. 356 & 0.45 & 7 & 7 & - & - & 10 \\
\hline \multirow{2}{*}{\multicolumn{2}{|c|}{ Positive Control }} & $\begin{array}{l}\text { Chloramphenicol } \\
\qquad(10 \mu \mathrm{g})\end{array}$ & $\begin{array}{c}\text { Chloramphenicol } \\
\text { B }(10 \mu \mathrm{g})\end{array}$ & $\begin{array}{c}\text { Amphotericin } \\
\mathrm{B}(10 \mu \mathrm{g})\end{array}$ & $\begin{array}{c}\text { Amphotericin } \\
\mathrm{B}(10 \mu \mathrm{g})\end{array}$ & $\begin{array}{c}\text { Streptomycin } \\
\text { sulfate } \\
(2 \mu \mathrm{g})\end{array}$ \\
\hline & & 15 & 15 & 13 & 15 & 25 \\
\hline \multicolumn{2}{|c|}{$\begin{array}{c}\text { Negative Control } \\
(15 \mu \mathrm{g})\end{array}$} & - & - & - & - & - \\
\hline
\end{tabular}

Antimicrobial activity: inhibition zone (mm): $50 \mu \mathrm{g} / \mathrm{disk}$; disk diameter: $6 \mathrm{~mm}$;

concentration of sample: $10 \mathrm{mg} / \mathrm{mL}$

(-): no activity; (EtOH crude extracted from liquid sample $50 \mathrm{~mL}$ )

Dextrose; and $0.03 \mathrm{~g}$ Catalase. Inoculum of strains M. smegmatis NBRC 3207; NBRC 3207 was cultured in media containing: $9 \mathrm{~mL}$ Middlebrook $7 \mathrm{H} 9,1 \mathrm{~mL}$ Middlebrook OADC, at $37{ }^{\circ} \mathrm{C}$ and incubate for 2 days and adjusted. Medium of the antimicrobial assay (anti TB) M. smegmatis for 100 $\mathrm{mL} \mathrm{H}_{2} \mathrm{O}$ : containing 0.52 gr Middlebrook Broth 7H9; $10 \mathrm{~mL}$ (10\%) Middlebrook OADC; $1.5 \mathrm{gr}$ Agar; $50 \mu \mathrm{L}$ Polysorbate 80 (Tween); $500 \mu \mathrm{L}$ Glycerol.

\section{RESULTS AND DISCUSSION}

In this research, we found nine marine sponges collected by scuba diving at Bunaken Island in Manado Indonesia, in 2014. We presented our sample in code number due to their molecular identification is still in progress. The dried crude extract was put into a glass vials, weighed and tested as a crude extract ethanol for screening the antimicrobial activity (Table 1 ).

\section{ODS Fractions Column Chromatography}

The EtOH extract of the nine-sample residue was separated into seven fractions (Fr. 1-7) by an ODS column $(100 \mathrm{~g})$ with the stepwise elution of $\mathrm{CH}_{3} \mathrm{OH}$ in $\mathrm{H}_{2} \mathrm{O}$. $(0 \%, 20 \%, 40 \%, 60 \%, 80 \%, 100 \%$, $100 \%+0.05 \%$ TFA) (Table 2) and were tested against bacteria $M$. smegmatis NBRC 3207 to observe the inhibition zone of marine sponges. The concentration of samples was arranged from 10, 20, $30 \mu \mathrm{g} /$ disk (Table 3).

\section{Screening Bioassays Antimicrobial}

Antimicrobial screening of EtOH crude

Table 2. Weight of ODS fractions of marine sponges

\begin{tabular}{lcrrrrrrr}
\hline $\begin{array}{c}\text { Sample } \\
\text { Code }\end{array}$ & $\begin{array}{c}\text { Weight of } \\
\text { Sample }\end{array}$ & $0 \%$ & $20 \%$ & $40 \%$ & $60 \%$ & $80 \%$ & $100 \%$ & $+0.05 \%$ TFA \\
& (g) & 1 & 2 & 3 & 4 & 5 & 6 & 7 \\
\hline SP. 102 & 16.76 & 4380.00 & 3710.00 & 3760.00 & 1780.00 & 2320.00 & 624.14 & 2700.00 \\
SP. 135 & 11.00 & 7320.00 & 675.79 & 540.36 & 682.48 & 1310 & 315.22 & 474.39 \\
SP. 137 & 11.80 & 7090.00 & 805.78 & 552.19 & 1040 & 414.91 & 448.02 & 325.70 \\
SP. 205 & 3.10 & 673.84 & 221.14 & 73.00 & 64.97 & 209.00 & 134.70 & 12.95 \\
SP. 206 & 10.50 & 6010.00 & 298.21 & 106.29 & 220.36 & 133.83 & 843.83 & 223.40 \\
SP. 259 & 0.60 & 266.05 & 107.36 & 11.64 & 5.32 & 8.88 & 31.68 & 111.51 \\
SP. 323 & 1.50 & 897.15 & 119.52 & 108.45 & 75.60 & 106.77 & 72.91 & 183.12 \\
SP. 352 & 1.75 & 944.91 & 219.91 & 123.02 & 59.59 & 42.60 & 81.40 & 255.42 \\
SP. 356 & 0.40 & 133.41 & 56.28 & 23.24 & 17.28 & 31.84 & 75.82 & 91.61 \\
\hline
\end{tabular}


Table 3. Antimicrobial assay of marine sponges ODS fractions against Mycobacterium

\begin{tabular}{|c|c|c|c|c|c|c|c|c|}
\hline \multirow[t]{2}{*}{$\begin{array}{l}\text { Sample } \\
\text { Code }\end{array}$} & \multirow{2}{*}{$\begin{array}{l}\text { Concen- } \\
\text { trations } \\
(\mu \mathrm{g} / \text { disk })\end{array}$} & \multicolumn{7}{|c|}{$\begin{array}{c}\text { (Inhibition Zone-mm; } \mu \mathrm{g} / \mathrm{mL} \text { ) } \\
\text { Fractions }\end{array}$} \\
\hline & & 1 & 2 & 3 & 4 & 5 & 6 & 7 \\
\hline \multirow[t]{3}{*}{ SP. 102} & 10 & - & - & - & - & - & - & - \\
\hline & 20 & - & - & - & - & - & - & - \\
\hline & 30 & - & - & - & - & - & - & - \\
\hline \multirow[t]{3}{*}{ SP. 135} & 10 & - & - & - & - & - & - & - \\
\hline & 20 & - & - & - & - & - & - & - \\
\hline & 30 & - & - & - & - & - & - & - \\
\hline \multirow[t]{3}{*}{ SP. 137} & 10 & - & - & - & - & - & - & - \\
\hline & 20 & - & - & - & - & - & - & - \\
\hline & 30 & - & - & - & - & - & - & - \\
\hline \multirow[t]{3}{*}{ SP. 205} & 10 & - & - & 10 & 8 & 8 & 8 & 8 \\
\hline & 20 & - & - & 13 & 11 & 8 & 11 & 11 \\
\hline & 30 & - & - & 15 & 11 & 10 & 11 & 11 \\
\hline \multirow[t]{3}{*}{ SP. 206} & 10 & - & - & - & - & - & - & - \\
\hline & 20 & - & - & - & 10 & 10 & 10 & 8 \\
\hline & 30 & - & - & - & 10 & 9 & 9 & 9 \\
\hline \multirow[t]{3}{*}{ SP. 259} & 10 & - & - & - & - & - & - & - \\
\hline & 20 & - & - & - & - & - & - & - \\
\hline & 30 & - & - & - & - & - & - & - \\
\hline \multirow[t]{3}{*}{ SP. 323} & 10 & - & - & 9 & 11 & 11 & 8 & - \\
\hline & 20 & - & - & - & 16 & 14 & 19 & 14 \\
\hline & 30 & - & - & - & 21 & 21 & 21 & 16 \\
\hline \multirow[t]{3}{*}{ SP. 352} & 10 & - & - & - & - & - & - & - \\
\hline & 20 & - & - & - & - & - & - & - \\
\hline & 30 & - & - & - & - & - & - & - \\
\hline \multirow[t]{3}{*}{ SP. 356} & 10 & - & - & - & 8 & 10 & 8 & - \\
\hline & 20 & - & - & - & 11 & 11 & 9 & 8 \\
\hline & 30 & - & - & - & 8 & 13 & 13 & 9 \\
\hline \multicolumn{9}{|c|}{$\begin{array}{l}\text { Positive Control - Streptomycin sulfate } \\
\text { Negative Control - MeOH }(20 \mu \mathrm{g}):- \\
\text { Antimicrobial activity: }(-) \text { : no activity }\end{array}$} \\
\hline
\end{tabular}

extracts of the nine sponges are shown in Table 1. All marine sponges extract inhibited the growth of $M$. smegmatis, but only SP.352, SP.356 inhibited $S$. aereus, while SP.356 inhibited E. coli.

The ODS fraction for all specimens were screened against $M$. smegmatis (based on their activities in ethanol crude extracted) and the result shown in Table 3 and Figure 1. Marine sponges SP.205, SP.206, SP.323 and SP.356 inhibited the growth of M. smegmatis. ODS fraction of SP.205 inhibited all the concentrations of the sample (at 10, 20, $30 \mu \mathrm{g} / \mathrm{disk})$ from Fr. 3-7. Fractions of SP.206, inhibited $M$. smegmatis at the Fractions 4-7, at concentration 20 and $30 \mu \mathrm{g} /$ disk, Fractions of SP.323 inhibited $M$. smegmatis at the Fractions 4-7, at concentration at $10,20,30 \mu \mathrm{g} /$ disk, while SP.356 inhibited the non-pathogen bacteria $M$ smegmatis at fractions 4-7. The results showed that SP.323 revealed the highest inhibiting activity against the growth of M. smegmatis. It is therefore have a high prospect to continue for the next other purification and NMR analysis.

Based on interpretive diffusion disk (CLSI, 2013), which shown in Table 3 and Figure 1, it can be concluded that marine sponges SP.205, SP.206 and SP.356 were categorized as Resistant (R) with diameter of the inhibition zone range $\leq 14 \mathrm{~mm}$, while SP.323 showed Intermediate (I) $15-19 \mathrm{~mm}$ on fractions 3-6 at sample concentration $10 \mu \mathrm{g} /$ disk. Sample concentration 20 and $30 \mu \mathrm{g}$ of SP.323 were categorized Susceptible $(\mathrm{S}) \geq 20 \mathrm{~mm}$.

Maarisit et al. (2017) obtained haliclocyclamines A-C and cyclostellettamines A-C, E-F from Haliclona sp. collected in Manado and found that these compounds have antimicrobial activity against

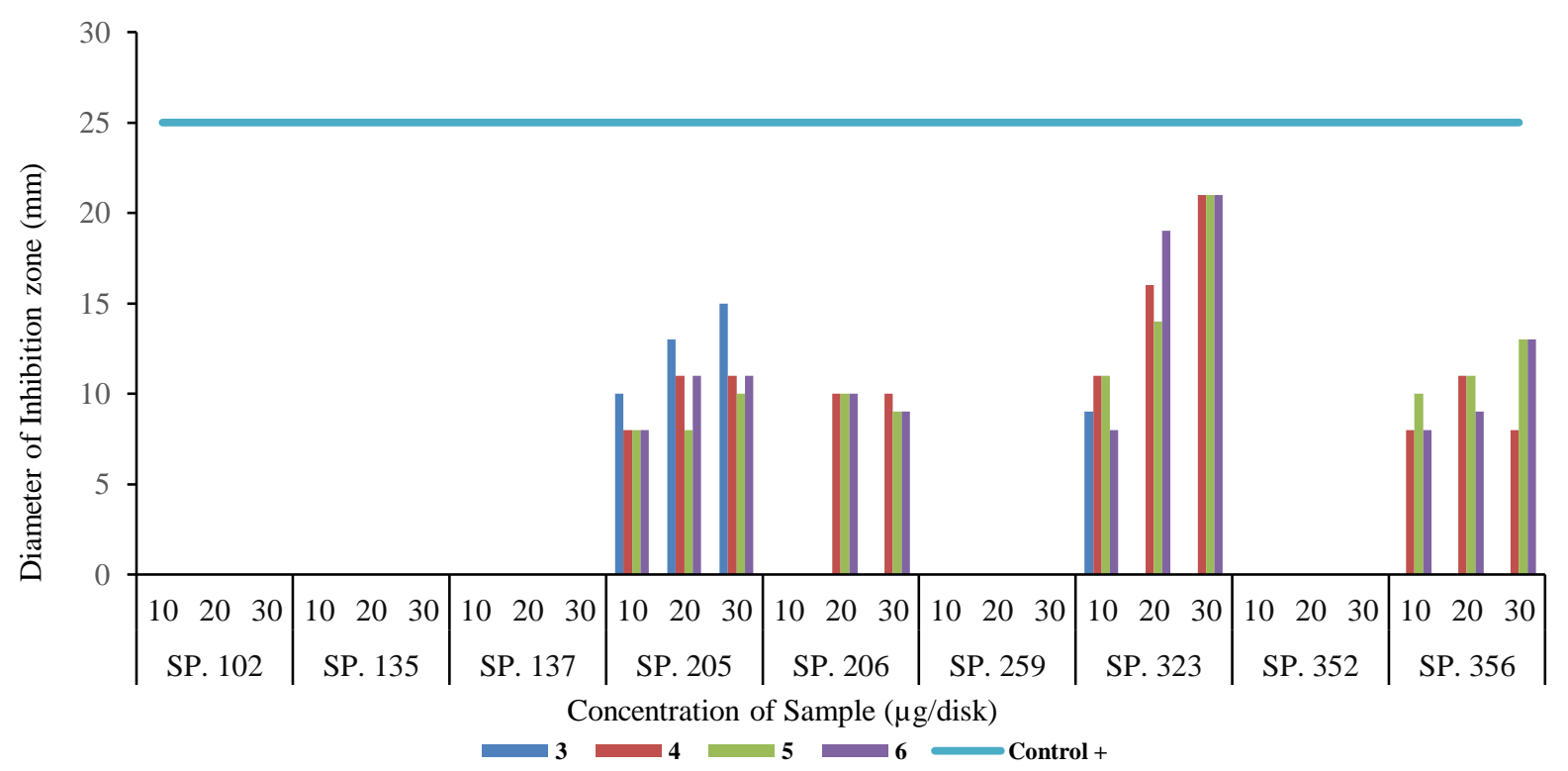

Figure 1. Antimicrobial assay of marine sponges ODS fractions against Mycobacterium smegmatis 
M. smegmatis with inhibition zone of $17,10,13,14$, $8,8,12$, and $12 \mathrm{~mm}$, respectively at $10 \mu \mathrm{g} /$ disk, Maarisit et al. (2017) found that Haliclona sp.have Resistant (R) and Intermediate (I) to M. smegmatis with diameter of the inhibition zone range $\leq 14 \mathrm{~mm}$ and $15-19 \mathrm{~mm}$, respectively. Indonesian marine sponge, Agelas sp., was observed by Abdjul et al. (2017) and obtained two compunds 5bromophakelline and leucettamol A, leucettamol A exhibited moderate anti mycobacterial activity, with inhibition zones of $7,9,12 \mathrm{~mm} /$ disk at 10, 20, $50 / \mu \mathrm{g} / \mathrm{disk}$. Similar to the results observed by Abdjul et al. (2016), for antimycobacterial activities of Okinawan sponge Halichondria panicea against $M$. smegmatis, the results showed inhibition zones range from $7-16 \mathrm{~mm}$ at $10 / \mu \mathrm{g} / \mathrm{disk}$. The difference in the inhibition of each extract against bacteria can be influenced by the structure and composition of bacteria cell, the density/concentration of bacterial cells and the composition of the active compound contained in the extract.

The standard concentration according to CLSI (2013) is $30 \mu \mathrm{g}$ per disk, and when compared in this study, which the concentrations range between 10 , $20,30 \mu \mathrm{g}$, it is necessary to do more research to produce accurate data with the aim of obtaining standard categories Resistant (R), Intermediate (I) and Susceptible (S).

In general, the best concentration required for antimicrobial activity is the lowest concentration while A larger zone of inhibition usually means that the antimicrobial is more potent.

Based on the interpretive diffusion disk, marine sponges SP.323 as an inhibitor and more potent to inhibit the growth of non-pathogen bacteria M. smegmatis. This sponge SP.323, might be recommended for detailed research for structure elucidation and other synthesis experiments, to develop as a new promising antibacterial drug.

\section{CONCLUSION}

Marine sponges collected in Bunaken Island in this research were found to have inhibiting activities against the growth of nonpathogenic $M$. smegmatis. Among nine marine sponges, it can be concluded that, marine sponges SP.323 can be used for further experimental analysis as an inhibitor. Its antimicrobial activity needs to be justified and purified with NMR analysis for structure elucidation.

Acknowledgement. The author wants to thank Prof. M. Namikoshi, Ph.D. and Dr. H. Yamazaki for the facilities during this research in TMPU Sendai Japan;
Dr. H. Rotinsulu and Dr. D.S. Wewengkang for collecting marine sponges specimen; to Dr. W. Maarisit for helping in antimicrobial assay; and to R.A.J. Lintang for reading the manuscript. "We certify that there is no conflict of interest with any organization regarding the materials discussed in this manuscript".

\section{REFERENCES}

ABDJUL, D.B., YAMAZAKI, H., KANNO, S., TOMIZAWA, A., WEWENGKANG, D.S., ROTINSULU, H., SUMILAT, D.A., UKAI, K., KAPOJOS, M.M. and NAMIKOSHI, M. (2017) An Anti-mycobacterial Bisfunctionalized Sphingolipid and New Bromopyrrol Alkaloid from the Indonesian Marine Sponge Agelas sp. Journal of Natural Medicines, 71 (3), pp. 531536.

ABDJUL, D.B., YAMAZAKI, H., KANNO, S., TAKAHASHI, O., KIRIKOSHI, R., UKAI, K., and NAMIKOSHI, M. (2016) Haliclonadiamine derivatives and 6-epi-Monanchorin from the marine sponge Halichondria panicea collected at Iriomote island. Journal of Natural Products, 79 (4), pp. 1149-1154.

BU, Y.Y., YAMAZAKI, H., UKAI, K. and NAMIKOSHI, M. (2014) Anti-mycobacterial nucleoside antibiotics from a marine-derived Streptomyces sp. TPU1236A. Marine Drugs, 12 (12), pp. 6102-6112.

CARROLL, A.R., COPP, B.R., DAVIS, R.H., KEYZERS, R.A. and PRINSEP, M.R. (2020) Marine natural products. Natural Product Reports, 37, pp. 175-223.

CLSI (2013) Performance Standards for Antimicrobial Susceptibility Testing; TwentyThird Informational Supplement M100-S23; Clinical and Laboratory Standards Institute: Wayne, PA, USA. p. 205.

EBADA, S.S., EDRADA, R.U., LIN, W. and PROKSCH, P. (2008) Methods for isolation, purification and structural elucidation of bioactive secondary metabolites from marine invertebrates. Nature Protocols, 3 (12), pp. 18201831.

MAARISIT, W., YAMAZAKI, H., ABDJUL, D.B., KATO, H., ROTINSULU, H., WEWENGKANG, D.S., SUMILAT, D.A., KAPOJOS, M.M., UKAI, K. and NAMIKOSHI, M. (2017) Anti-Mycobacterial Alkaloids, Cyclic 3-Alkyl Pyridinium Dimers, from the Indonesian Marine Sponge Haliclona sp. Bioorganic \& Medicinal Chemistry Letters, 27 (15), pp. 3503-3506. 
Sumilat: Screening antibacterial activity ODS fractions of marine sponges against non-pathogenic ...

MEHBUB, M.F., LEI, J., FRANCO, C. and ZHANG, W. (2014) Marine Sponge Derived Natural Products between 2001 and 2010: Trends and Opportunities for Discovery of Bioactives. Marine Drugs, 12, pp. 4539-4577.

NEWMAN, D.J. and CRAGG, G.M. (2014) Marinesourced anti-cancer and cancer pain control agents in clinical and late preclinical development. Marine Drugs, 12 (1), pp. 255-278.

NEWMAN, D.J. and CRAGG, G.M. (2020) Natural Products as Sources of New Drugs over the
Nearly Four Decades from 01/1981 to 09/2019. Journal of Natural Products, 83 (3), pp. 770-803. SUMILAT, D.A. (2019) Antibacterial Activity ODS Fractions of Marine Sponge Auletta sp. against Mycobacterium smegmatis. Jurnal Ilmiah Platax, 7 (1), pp. 329-334.

WHO (2020) Global Tuberculosis Report 2020. Geneva: World Health Organization. p. 232. Licence: CC BY-NC-SA 3.0 IGO. ISBN 978-924-001313-1. 